\title{
Erratum: Activate lattice oxygen redox reactions in metal oxides to catalyse oxygen evolution
}

Alexis Grimaud, Oscar Diaz-Morales, Binghong Han, Wesley T. Hong, Yueh-Lin Lee, Livia Giordano, Kelsey A. Stoerzinger, Marc T. M. Koper and Yang Shao-Horn

Nature Chemistry 9, 457-465 (2017); published online 9 January 2017; addendum published after print 23 June 2017 ; corrected after print 21 December 2017.

In the version of this Article originally published, a typographical error meant that the unit on the $y$-axis label of Fig. $3 \mathrm{~b}$ incorrectly read ' $\mathrm{mA} \mathrm{cm}$ disk'; it should have read ' $\mathrm{mA} \mathrm{cm}$ oxide. This has been now corrected in the online versions of the Article. 